\title{
El realismo social e indigenista en el cuento ecuatoriano 1920-1950
}

\section{The Social and Indigenist Realism in the Ecuatorian Story 1920-1950}

\author{
MarCelo León CAstro [marcelo.leon@unileon.es] \\ Universidad Nacional de Loja, Ecuador \\ Paz Benito Del Pozo [paz.benito@unileon.es] \\ Universidad de León, España \\ Yovany SALAzar Estrada [ysalazarec2002@yahoo.es] \\ Universidad Nacional de Loja, Ecuador
}

\section{RESUMEN}

El artículo se propone justipreciar el advenimiento del realismo social e indigenista en la consolidación y florecimiento del cuento ecuatoriano, durante las décadas de los veinte, treinta y cuarenta de la centuria pasada. Para hacerlo, luego de compendiar el desarrollo cronológico del cuento en el Ecuador y de esbozar una breve contextualización de la época en que emergió el realismo se alude a los principales cuentistas y obras que, procedentes de distintas ciudades del país, han sido canonizados como referentes del realismo e indigenismo en la narrativa breve, incluidos aquellos cuentistas que prolongaron la vigencia de esta tendencia literaria en las décadas de los cincuenta y sesenta del siglo XX.

\section{Palabras clave}

Cuento realista; indigenismo; realismo social; Ecuador

\begin{abstract}
The article aims to appraise the advent of social and indigenous realism in the consolidation and flourishing of the Ecuadorian short story, during the twenties, thirties and forties of the last century. To do so, after abridging the chronological development of the short story in Ecuador and outline a brief contextualization of the time that realism emerged it is alluded to the main storytellers and works from different cities of the country which have been canonized as references of realism and indigenism in the brief narrative of our country, including those storytellers who extended the validity of this literary trend in the fifties and sixties of the twentieth century.
\end{abstract}

\section{KEYWORDS}

Realistic short story; indigenism; social realism; Ecuador 


\section{Un apunte cronológico en torno al cuento ecuatoriano}

Aunque con una ya dilatada y hasta milenaria trayectoria histórica en la manifestación oral popular, en la República del Ecuador existe un amplio consenso en el sentido de que el cuento literario tiene sus orígenes en los años finales del siglo XIX y primeros del XX, durante el período de influencia del romanticismo y el costumbrismo en la narrativa de ficción de este país (Cfr. Ubidia, 2006: 310). Entre los pioneros en el cultivo de este género es de justicia mencionar los nombres de Juan León Mera (1832-1894), Juan Montalvo (1832-1889), José Modesto Espinoza (1833-1916), José Antonio Campos (1868-1939), Modesto Chávez Franco (1872-1952), Luis Napoleón Dillon (1875-1929), Elysa Ayala González (1879-1956) y Héctor Manuel Carrión (1878-1929) (Cfr. Salazar 2016: 4-6).

Sin embargo, la época de consolidación y florecimiento del cuento literario en el Ecuador coincide con los años de surgimiento y predominio hegemónico del realismo social e indigenismo, en las décadas de los veinte, treinta y cuarenta del siglo XX, período que constituye la "época de oro de la narrativa ecuatoriana" (Ubidia 2006: 311), con la presencia de varios narradores que han dejado una huella indeleble, tal como se demuestra en la parte central de este artículo y como lo evidencian los " 28 nuevos autores, que se lanzan al terreno de la cuentística, con un total de 37 libros publicados” (Martínez 2015: 255-256).

A la predominancia del realismo social e indigenismo en el cuento ecuatoriano, le sucede la llamada generación de transición, en las décadas de los cincuenta y sesenta, época en la que se desarrollan al menos dos tendencias muy bien diferenciadas entre los escritores que trabajan en el género narrativo en estudio (Cf. Calderón, 1997: 16). Por un lado, está la obra cuentística de quienes prolongan la estética realista social e indigenista de los años anteriores: Pedro Jorge Vera (1914-1999), Adalberto Ortiz (1914-2003) y María Corylé (1901-1978). De otro lado comienzan a emerger los cuentistas que elaboran sus obras de narrativa breve, en el marco de la nueva estética del cuento hispanoamericano de esos años, con autores como: César Dávila Andrade (1918-1967), Alejandro Carrión Aguirre (1915-1992), Augusto Mario Ayora (1920-1980), Rafael Díaz Ycaza (1925-2013), Alcino Ramírez Estrada (1930), Wálter Bellolio (1930-1974), Eugenia Viteri (1930), Miguel Donoso Pareja (1931-2015) y Juan Andrade Heyman (1945).

Con las transformaciones sociales surgidas en el escenario internacional y el nuevo contexto sociocultural y literario que con base en él emergió en el Ecuador, a partir de la década de los sesenta del siglo anterior hace su presencia una nueva generación de cuentistas, los cuales comienzan a publicar a partir de los años setenta y un gran número de ellos se han mantenido en plena producción escrituraria, incluso hasta los primeros años del siglo XXI. Con estos escritores retoma un nuevo impulso el cuento ecuatoriano, así "entre 1963 y 1968, se produce un aumento notable en la publicación de libros de cuentos", con la edición de 21 títulos y "entre 1969 y 1977 , hay un auge vertiginoso en la producción de cuentos con 64 libros publicados" (Martínez 2015: $268,271)$. A las diversas temáticas que abordan en sus obras creativas se las puede agrupar en cuatro grandes campos:

La representación de los espacios urbanos de Quito, Guayaquil y Cuenca, con cuentistas como Raúl Pérez Torres (1941), Marco Antonio Rodríguez (1942), Vladimiro Rivas Iturralde (1944), Francisco Proaño Arandi (1944), Abdón Ubidia (1944), Javier Vásconez (1946), Jorge Dávila Vázquez (1947), Eliécer Cárdenas Espinoza (1950), Ramiro Arias Barriga (1954), y Ernesto Torres Terán 
(1956), en cuyos textos se presentan escenarios, tramas narrativas y personajes que patentizan los radicales cambios en las ya citadas tres principales ciudades del Ecuador (cf. Salazar 2016: 24 y ss.).

La alusión a los sujetos marginales, que habitan las urbes más pobladas del Ecuador y ponen la nota disruptiva al orden social establecido desde la clase hegemónica en el poder se pone de manifiesto en los cuentos de autoría de Javier Vásconez, Huilo Ruales Hualca (1947), Edwin Ulloa Arellano (1947), Jorge Velasco Mackenzie (1949), Ernesto Torres Terán y Raúl Vallejo Corral (1959).

Los temas del amor y el erotismo han sido trabajados por muchos cuentistas ecuatorianos, los cuales han publicado su obra narrativa desde la década de los setenta del siglo anterior hasta los años más recientes, conforme lo patentizan los cuentos de Miguel Donoso Pareja, Modesto Ponce Maldonado (1938), Raúl Pérez Torres, Abdón Ubidia, Francisco Proaño Arandi, Carlos Carrión Figueroa (1944), Iván Egüez (1944), Huilo Ruales Hualca, Jorge Velasco Mackenzie, Eliécer Cárdenas Espinoza, Galo Galarza Dávila (1956), Raúl Vallejo Corral, Raúl Serrano Sánchez (1962), Lucrecia Maldonado Rodríguez (1962), Carolina Andrade Freire (1963), Cristóbal Zapata Carpio (1968), Gabriela Alemán (1968), Marcelo Báez (1969), Yanna Hadatty Mora (1969), Solange Rodríguez Pappe (1976), Miguel Antonio Chávez (1979) (cf. Ortega 2011: 188-198; Vallejo 2013: 5-19) y otros cuentistas más jóvenes.

El tratamiento de la ciencia ficción y lo fantástico es otra de las preocupaciones de los cuentistas ecuatorianos que escribieron su obra a partir de la década de los setenta, en cuyos ámbitos si bien ha existido poca producción, en el subgénero de la ciencia ficción han emergido nombres significativos, entre los que merece destacarse Carlos Béjar Portilla (1938), Abdón Ubidia, Santiago Páez (1958) y Solange Rodríguez Pappe; y, en lo fantástico se puede incluir a cuentistas, también, de indudable calidad, como Juan Valdano Morejón (1940), Jorge Dávila Vázquez, Luis Salvador Jaramillo (1955) y José Rodrigo Sánchez Puertas (1973) (cf. Salazar 2016: 32-35).

Con los cambios que, en beneficio de la equidad de género y el consecuente acceso de las mujeres a las diferentes actividades intelectuales y artísticas que se han producido dentro y fuera del Ecuador, durante las últimas décadas, ha emergido, asimismo, una significativa presencia femenina en el cultivo del cuento en el Ecuador. Dentro de este grupo de creadoras sobresalen algunas cuentistas que han venido dando su aporte desde la década de los treinta del siglo anterior y otras más jóvenes que continúan con su labor creativa en los años más recientes y hasta la actualidad, entre las que, además de las ya citadas en líneas anteriores, amerita mencionarse: Nela Martínez (1912-2004), Zoila María Castro (1917), Alicia Yánez Cossío (1929), Lupe Rumazo (1933), Fabiola Solís de King (1933), Ana María Iza (1941), Violeta Luna (1943), Gilda Holst Molestina (1952), Liliana Miraglia (1952), Jennie Carrasco Molina (1955), Aminta Buenaño Rogel (1958), María Eugenia Paz y Miño (1959), Martha Rodríguez Albán (1959), y Ruth Patricia Rodríguez Serrano (1966) (cf. Ortega 2011: 179 y ss.).

La narrativa y el cuento infantil y juvenil, en el Ecuador durante los últimos años, ha cobrado una notable presencia y en su cultivo y difusión destacan varios cuentistas, cada uno de ellos con una ingente cantidad de obra publicada y reconocimientos recibidos, dentro y fuera del país, entre los principales creadores es necesario destacar los nombres de Edna Iturralde (1948), Francisco Delgado Santos (1950), Leonor Bravo Velásquez (1953), Soledad Córdova (1957), Edgar Alan García (1958) y María Fernanda Heredia (1970) (cf. Salazar 2016: 39-42).

En las últimas dos décadas del siglo anterior, que arrancan con la vuelta a la democracia en el año de 1979, a decir de la profesora Juana Martínez Gómez, el cuento adquiere un lugar relevante 
dentro de la literatura ecuatoriana, gracias a la "renovación de medios de difusión y estímulo como la creación de nuevos concursos, revistas, editoriales, talleres literarios, etc. En los últimos 23 años del siglo XX aparecen unos 125 autores nuevos y se publican 265 libros, más de la mitad de todos los publicados en la centuria" (Martínez 2015: 276).

En los primeros años del siglo XXI, entre los noveles cultores del cuento en el Ecuador, se advierte una auténtica multiplicación temática y no obstante la juventud de la mayoría de ellos, ya se toman en cuenta los siguientes creadores de narrativa breve: Paúl Hermann (1973), Esteban Mayorga (1977), Eduardo Varas (1979), Silvia Stornaiolo (1980), Edwin Alcarás (1981), Jorge Luis Cáceres (1982), Carlos Santiago Quizhpe Silva (1982), Andrés Cadena (1983) y Ángel Darío Jiménez Gaona (1984).

La profusión de nuevos y, en varios casos, bien dotados cultores de la narrativa breve en el Ecuador, que se patentiza con la incompleta enumeración antes realizada, constituye una clara muestra de que el cuento ecuatoriano sigue gozando de buena salud y que, con seguridad, se seguirá disfrutando y aprendiendo de nuevas obras creativas, de indudable calidad y trascendencia (cf. Salazar 2016: 42-47).

\section{Breve contextualización de la época en que emerge el realismo social e indigenista}

En una línea de continuidad de la mímesis aristotélica, que se refiere a las relaciones entre literatura y realidad, el realismo alude a "una categoría estética o rasgo de las obras literarias, consistente en su referencia o vinculación con la realidad, imitada o representada en ellas" (Estébanez 1999: 900). El realismo se refiere, también, a la "reproducción estética fiel y no distorsionada de los fenómenos externos tal y como son percibidos por nosotros" (Villanueva 2004: 31).

Dentro de la escuela literaria realista hay que hacer mención, además, al realismo social, cuya preocupación central, en el caso de la narrativa española y que mutatis mutandis se corresponde con la ecuatoriana, es "ofrecer un testimonio de denuncia de la realidad socioeconómica y política del país, a la vez que persiguen una función informativa (ante la ocultación oficial y tergiversación de los medios de comunicación) y de revulsivo frente al orden establecido". En este tipo de literatura la denuncia se presenta en dos campos precisos: "el de la injusticia social, de la que son objeto los trabajadores del campo y la industria, y la falta de conciencia moral de las clases dirigentes responsables de esta situación, en especial, la burguesía" (Estébanez 1999: 906).

El realismo social en la narrativa ecuatoriana, en criterio de uno de sus mejores cultores, constituye "una manera, o mejor, una serie ordenada de maneras de mostrar esa realidad, que en último término se reduce a exhibirla lo más cruda y descarnadamente posible, sin sujetarse a la continencia de prejuicios" (Cuadra 2003: 470). El autor citado, más adelante enfatiza que en este tipo de obra narrativa no basta con presentar "la realidad y nada más que la realidad" sino que "la escoge, la traduce y la empuja a servir propósitos, en cuanto busca con eso delatar las injusticias de la organización que rige nuestra vida social [...]. Valiéndose de todo esto, la literatura de contenido denunciará y protestará" (471).

En el Ecuador, el compromiso asumido por el escritor de narrativa de ficción, como era de esperarse, despertó enconadas polémicas e incluso en los años más recientes ha generado opiniones 
críticas como la de Leonardo Valencia, quien plantea la metáfora del Síndrome de Falcón ${ }^{1}$ para referirse al peso que debe cargar el escritor ecuatoriano, como consecuencia de la responsabilidad social autoimpuesta, por cuanto "la literatura, bajo ese punto de vista, debe ser útil e importante, debe ser seria. A esa autocensura la denominé, un poco en broma, el Síndrome de Falcón: el escritor ecuatoriano debía cargar, como Falcón, una agenda secreta y no declarada para su literatura" (Valencia 2008). Sin embargo, este mismo autor reconoció con mucha anterioridad que los narradores del realismo social, durante las décadas de los treinta y cuarenta del siglo anterior, lograron una posición central y hasta hegemónica en la literatura ecuatoriana porque contaban con las virtudes del aliento narrativo motivado por la responsabilidad política y un manojo de buenas intenciones que "decidieron cargar en sus hombros. Les favorecía la corriente de los tiempos, preocupada por concederles a los escritores una vocación mesiánica, contaban con la aceptación general de los grupos literarios y la difusión de un tenaz proselitismo puntillosamente llevado a cabo" (Valencia 2000: 335).

Para comprender mejor el nivel de importancia que obtuvo el realismo social en el Ecuador es necesario recordar que, desde una perspectiva ideológica, a inicios del siglo XX, en el seno del liberalismo radical ecuatoriano emergen los primeros gérmenes del pensamiento socialista, nuevas ideas políticas que, poco a poco, se van consolidando y organizando en el país hasta integrarse como Partido Socialista Ecuatoriano (PSE), en el año de 1926 y Partido Comunista del Ecuador (PCE), en 1931, en un período histórico de "persistente inestabilidad y crisis política, que se inicia con la llamada Revolución Juliana del 9 de julio de 1925, y termina hacia 1948-1949, con el auge de la exportación bananera, con una más acentuada articulación del país al circuito capitalista mundial" (Proaño 2007: 123). Producto de la influencia de estas ideas políticas de la izquierda marxista ecuatoriana se produce la primera huelga y masacre obrera en la ciudad de Guayaquil, el 15 de noviembre de 1922, la Guerra de los cuatro días, en Quito en 1932 y la Gloriosa Revolución del 28 de mayo de 1944, que echó del poder a Carlos Alberto Arroyo del Río, acusado de ser el principal responsable de no contener a tiempo la invasión peruana de 1941 y de firmar el nefasto Protocolo de Río de Janeiro, el 29 de enero de 1942, en condiciones muy desventajosas para el Ecuador.

A estas condiciones internas se suma la influencia de la Revolución Mexicana de 1910, el triunfo de la Revolución bolchevique de Rusia, en octubre de 1917, la Primera Guerra Mundial de 1914-1918, el Movimiento Estudiantil Universitario de Córdoba de 1918, la crisis del capitalismo mundial, cuyos momentos más agudos fueron la recesión de 1920-1922 y el Crac Financiero de 1929, la divulgación de las teorías freudianas, el surgimiento de movimientos artísticos y literarios profundamente renovadores (realismo social o vanguardias), y la creación de los primeros partidos socialistas en América Latina. También fue gravitante la influencia de los clásicos del pensamiento marxista latinoamericano, como el peruano José Carlos Mariátegui (1894-1930), el argentino Aníbal Ponce (1898-1938) y el cubano Julio Antonio Mella (1903-1929).

Es obvia, asimismo, la impronta devenida de las lecturas de los narradores naturalistas, como los franceses Emilio Zola (1840-1902) y Henri Barbusse (1873-1935) o el español Pío Baroja

1 La metáfora se inspira en Juan Alberto Falcón Sandoval (1912-2005), un humilde hombre de pueblo que se hizo famoso por haber cargado en sus hombros por doce años (1935-1947) al escritor, periodista, político de izquierda y suscitador cultural guayaquileño Joaquín Gallegos Lara (1911-1947), integrante del “Grupo de Guayaquil”, autor de la novela Las cruces sobre el agua (1946) y coautor del emblemático libro de cuentos del realismo social Los que se van (1930), quien tenía una enfermedad congénita que le impedía caminar. 
(1872-1956), así como de las emblemáticas novelas americanas de la tierra: La vorágine (1924), de José Eustasio Rivera (1888-1928); Don Segundo Sombra (1926), de Ricardo Güiraldes (18861927); y Doña Bárbara (1929), de Rómulo Gallegos (1884-1969).

En este momento de la historia del Ecuador, en el que confluyen una serie de ideas renovadoras en los ámbitos social, cultural y literario, la ideología socialista hizo sentir su preponderante influjo. Y dentro de la literatura fue la narrativa de ficción el género que mejor se nutrió de las ideas socialistas, comunistas y de renovación que hicieron su vigorosa presencia en el país, a partir de la década de los veinte y que constituyeron el detonante para el surgimiento de la "edad de oro" de la narrativa ecuatoriana, entre las décadas de los 20 y 40 del siglo XX.

En esta nueva circunstancia de la historia del Ecuador, "el indio, el cholo, el montubio ${ }^{2}$, imponen ahora su presencia y con ella una problemática nueva, largamente escamoteada por la ideología aristocratizante y feudal de la colonia y de los primeros años de la república" (Vintimilla 1985: 254). Con la incorporación de nuevos actores sociales a la vida pública del país emergió la necesidad objetiva de una "ruptura en los campos de la poesía, la plástica, pero sobre todo en el relato y, más genéricamente, en el pensamiento, se evidenciaba ya, no solo por la rigidez de las formas académicas, sino en mayor medida porque la vida ecuatoriana exigía cada vez con mayor urgencia, nuevas formas de expresión que dieran cuenta de las realidades emergentes" (Vintimilla 1985: 261). El nivel de militancia ideológica y compromiso político de los escritores de la época se ponen en evidencia en los textos creativos, en los cuales se corrobora que los protagonistas son "la multiplicidad de sectores sociales que conforman la nación ecuatoriana y que, hasta entonces, habían permanecido desconocidos para la conciencia nacional oficial: los montubios de José de la Cuadra, los cholos de Demetrio Aguilera, los indios de Jorge Icaza, los obreros de Joaquín Gallegos Lara" (Vintimilla 1985: 270).

\section{El realismo social e indigenista en el cuento ecuatoriano}

Con fundamento en lo antes expresado y siguiendo la tradición realista social inaugurada por el liberal Luís A. Martínez (1869-1909), con su novela A la costa (1904), en el ámbito de la narrativa corta, el socialista Fernando Chávez (1902-1999) publica el cuento "La embrujada" (1923), triunfador en un concurso de relato criollo, cuya trama narrativa se movía entre el realismo social e indigenista y la vanguardia.

En esta misma perspectiva de renovación literaria es de grata recordación "La mala hora" (1927), de Leopoldo Benites Vinueza (1905-1995), cuento premiado en el Primer Concurso convocado por el Colegio Vicente Rocafuerte de la ciudad de Guayaquil, junto con "El enemigo", de ambiente indigenista. "La mala hora" trata sobre la vida del montuvio y constituye un paso más en el tratamiento realista de los problemas y personajes ecuatorianos. Por primera vez el montuvio

2 La Real Academia Española de la Lengua hasta la vigésima segunda edición de su Diccionario de la lengua española solo aceptaba la palabra montubio, con bilabial sonora (b), para aludir a una persona "montaraz, grosera"; sin embargo, en respuesta a los reclamos de las organizaciones campesinas de la región litoral del Ecuador y la iniciativa formulada por el Dr. Ángel Loor, Decano de la Facultad de Ciencias de la Comunicación de la Universidad San Gregorio de Portoviejo (cf. Sánchez 2015), en la última edición del 2014 ha incorporado, también, la palabra montuvio, con oclusiva bilabial sonora (v), como un ecuatorianismo utilizado para referirse al "campesino de la costa" (Real Academia Española, 2014). 
se convierte en protagonista dramático, pues, en "La mala hora", los abusos de los explotadores y sus sicarios desencadenan la ira de un montubio de la Costa ecuatoriana, que termina por dar muerte a sus verdugos y huir de la "justicia" (Salazar 2000: 7). Por ello se ha manifestado que con este cuento se "inaugura con madurez espiritual, idiomática y estilística el realismo ecuatoriano" (Rodríguez 1970: 9).

Aunque no en la misma línea del realismo social e indigenista es digna de mención la obra del pionero del vanguardismo ecuatoriano y militante socialista Pablo Palacio (1906-1947), quien desde su época de adolescente, en calidad de estudiante del Colegio Bernardo Valdivieso de la ciudad de Loja, ya había hecho conocer algunos de sus cuentos en revistas literarias de esta ciudad; sin embargo, en 1927 publicó el cuentario Un hombre muerto a puntapiés, en cuyos textos narrativos se advierte su espíritu iconoclasta, en tanto propone una modificación de actitud ante la vida, una negación consciente de los valores sociales enarbolados por la clase dominante, con cuentos poblados de personajes que constituyen verdaderos casos clínicos como "el vicioso, el antropófago, el pederasta, el sifilítico, el loco, el monstruo, el suicida” (Ortega 2004: 11-12). Su acerba crítica al orden social predominante y a la concepción estética vigente fue muy frontal, "Palacio parece haberse estado riendo a gusto mientras los redactaba. En estos las normas y las proporciones naturales se producen en contradicción a la representación caricaturesca; lo humorístico resulta del choque con alguna norma" (Robles 2000: 316).

En la línea del realismo social, en el año de 1930, se publica el libro de cuentos Los que se van: cuentos del cholo y del montubio, de autoría de tres jóvenes narradores guayaquileños, aún desconocidos hasta ese momento: Joaquín Gallegos Lara (1911-1947), Demetrio Aguilera Malta (1909-1981) y Enrique Gil Gilbert (1912-1973), libro de veinticuatro cuentos, ocho por cada autor, que se caracteriza por "un estilo conciso, hecho de frases cortas y rotundas, regadas en párrafos mínimos que guardan perfecta armonía con los acápites que fragmentan cada historia, también corta y rotunda. Localismos, malas palabras, expresiones directas: allí los personajes hablan como en la realidad" (Ubidia 2006: 311). Jorge Enrique Adoum también relieva el aporte de este libro en cuanto al uso del lenguaje, al manifestar que es "ese lenguaje nuevo, descarnado, insolente, incluso terrorista [...] contra la forma académica y el colonialismo lingüístico, lo que Los que se van aporta al nuevo relato" (Adoum, citado por Donoso 1984: 29).

Esta obra cumbre del realismo social ecuatoriano asombró por lo radical de su planteamiento estético y causó un verdadero revuelo. Se tildó a este tipo de literatura como "el producto de un plan político, que buscaba producir el escándalo internacional, el desprestigio de nuestro medio retrasado, revelando imprudentemente detalles vergonzosos de la explotación del hombre campesino y describiendo a este como una especie de subhombre movido por la lujuria, los celos, el alcohol, y a ratos por el instinto homicida" (Rojas 1948: 185). A diferencia de estos prejuicios que prevalecían en el entorno cultural de la época en el Ecuador, la valoración positiva del libro de cuentos vino desde el extranjero, remarcándose "el afortunado producto de un realismo descarnado y crudo, y de una gran sinceridad y honradez literaria" (Rojas 1948: 186).

Los tres narradores antes citados, a los que se les une José de la Cuadra (1903-1941) y Alfredo Pareja Diezcanseco (1908-1995), autor de un solo libro de cuentos: Los gorgojos (1954), conforman el afamado "Grupo de Guayaquil", comúnmente conocido como "Los cinco como un puño". Ya una vez integrados como grupo, se multiplican las publicaciones individuales, en el campo de la novela, el ensayo y el cuento. En narrativa corta, por ejemplo, merece destacarse Joaquín 
Gallegos Lara, quien a título personal solo publicó el relato póstumo "La última erranza" (1947), con un escenario y una cosmovisión propios del realismo social del que fue su principal teórico, animador y exégeta.

Enrique Gil Gilbert pone en circulación su colección de cuentos Yunga (tierra caliente) (1932), en el que consta "El negro Santander", acaso el mejor del libro y pionero en la representación y recreación literaria de la problemática de la emigración internacional originada en el Ecuador, que tiene como personaje protagónico a un negro traído desde Jamaica por la compañía norteamericana que se encargó de la construcción del ferrocarril para unir a las ciudades de Quito y Guayaquil, en los tiempos de Eloy Alfaro. Siete años después publica Los relatos de Emmanuel (1939), un libro de elevada prosa poética que narra el problema de los hijos ilegítimos. Casi tres décadas más tarde, en la misma línea realista social, edita una colección de seis cuentos, con el título del último de ellos: La cabeza de un niño en un tacho de basura y otros cuentos (1967).

José de la Cuadra inicia su labor creativa en el ámbito del cuento con relatos como "Oro de sol" (1925), "Perlita Lila” (1925), “Olga Catalina” (1925), "Sueño de una noche de navidad” (1930). Sus primeros cuentarios son El amor que dormía (1931) y Repisas (1932), con los que va revelándose "quien habría de ser, dentro de poco, el mejor de nuestros cuentistas" (Rojas 1948: 187). Después publica Horno (1932), La vuelta de la locura (1932) y Guasintón: relatos y crónicas (1938), en los cuales "su frase cortada, firme, de sabia adjetivación, expresaba solamente lo justo. En sus relatos no sobra una palabra. Una ironía fina y zumbona le ayudaba a evocar escenas y personajes" (Rojas 1948: 193). Estas indudables cualidades lo catapultan ya no solo como el maestro del "Grupo de Guayaquil" y de la "Generación del treinta" sino, a juicio personal, junto con Pablo Palacio (19061947) y César Dávila Andrade (1918-1967), como uno de los tres mejores cuentistas ecuatorianos de todos los tiempos.

De manera simultánea al desarrollo de la ingente producción narrativa del "Grupo de Guayaquil", despliega su actividad creativa la denominada "Generación del treinta”, con escritores que actuaron en torno a tres grupos que emergieron en tres de las principales ciudades de la Sierra ecuatoriana: Quito, Cuenca y Loja, que crearon su obra de narrativa de ficción, en los lindes de la estética realista social e indigenista.

En la ciudad de Quito, Jorge Icaza (1906-1978) publica Barro de la sierra (1934). De los seis cuentos que integran el libro, cuatro se pueden adscribir al realismo social y al indigenismo y están inspirados en los recuerdos de las duras condiciones de vida de los indígenas trabajadores de la hacienda de propiedad del tío Enrique Coronel, que el autor había conocido, de primera mano, durante sus tres años de permanencia en los parajes serraniegos de la provincia del Chimborazo, cuando aún era niño. Los otros dos, sobre todo "Interpretación", tienen clara influencia del psicoanálisis freudiano. En 1952 publica su segundo libro de cuentos Seis relatos, cuentario que dos años más tarde lo vuelve a publicar, en Buenos Aires, con el título de Seis veces la muerte. Ocho años más tarde publica Viejos cuentos (1960). De los Cuentos completos (2006), que se editaron con motivo del primer centenario de nacimiento de Jorge Icaza, debería mencionarse el relato largo "Mama Pacha", en el que se problematiza el trauma del mestizo ecuatoriano, "su doble naturaleza que lo obliga a exhibir sus ancestros blancos y ocultar los indígenas", a consecuencia de lo cual el protagonista del relato "prefiere penar por un crimen que no cometió antes que admitir que tiene una madre india” (Ubidia 2006: 312). 
En la misma ciudad capital del Ecuador, otro cuentista que dejó una profunda huella es Jorge Fernández (1912-1979), con Antonio ha sido una hipérbole (1933), en cuyos textos si bien la acción ya transcurre en la ciudad, la escritura evidentemente se mueve dentro de los planteamientos estéticos del realismo social del “Grupo de Guayaquil”, que aún se encontraba en plena efervescencia. Y Sergio Núñez (1896-1982), en la misma línea indigenista de Jorge Icaza, publicó dos libros de cuentos: Novelas del páramo y la cordillera (1934) y Tierra de lobos (1934).

En Cuenca, las obras y autores más destacados de esta época son los siguientes: Cuentos mor$\operatorname{lacos}^{3}$ (1931), de Manuel Muñoz Cueva, quien desarrolla en algunas de sus creaciones narrativas el tema indigenista y logra "un cuento de vibración y angustia que lo emparentaba con los nuevos modos narrativos" (Rodríguez 1970: 10); Llegada de todos los trenes del mundo (1933), de Alfonso Cuesta y Cuesta (1912-1991), alterna el tema urbano mestizo con el campesino indígena y su obra cuentística está vinculada a las propuestas del indigenismo y la denuncia social y en sus textos ficticios, además, se alude a la "conmiseración por los niños desvalidos y la denuncia de crueles injusticias” (Rodríguez 1970: 10); y Barro de siglos (1934), de César Andrade y Cordero, en similar tendencia temática y formal (cf. Rojas 1948: 189-190).

En la ciudad de Loja, en el ámbito del cuento es destacable el nombre de Eduardo Mora Moreno (1906-1987), quien con sobra de méritos ha sido reconocido como precursor, pionero e iniciador de la narrativa realista social e indigenista en la literatura ecuatoriana con sus relatos tardíamente reunidos en el cuentario Humo en las eras (1939) y otros cuentos que ya fueron publicados en las revistas literarias lojanas de la primera parte del siglo XX, como: Alba Nueva (1923), Loxa (1924), Revista del Colegio Bernardo Valdivieso (1925-1930), Hontanar (1931), Bloque (1935), Revista de Cultura (1939), entre otras. Similar contribución, a la consolidación de la literatura indigenista del Ecuador, ha realizado el animador espiritual de las nuevas generaciones e inolvidable rector del Colegio Bernardo Valdivieso de Loja, Dr. Carlos Manuel Espinosa, con cuentos publicados, desde el año 1926, en algunas de las revistas lojanas antes mencionadas.

De esta misma ciudad se tiene que mencionar a Ángel Felicísimo Rojas (1909-2003), quien es autor de dos cuentarios: Un idilio bobo (1946), publicado en la imprenta de la Casa de la Cultura Ecuatoriana, que "se convierte en el mayor centro editorial de apoyo al cuento ecuatoriano con alrededor de 150 libros de cuentos publicados hasta finales del siglo XX" (Martínez 2015: 261) e integrado por quince cuentos, cuyos ambientes, en su mayoría, pertenecen al universo rural de la provincia de Loja y la Región Sur del Ecuador. En esta obra de narrativa breve confluyen dos vertientes, "una indigenista [...] y otra urbana" (Rodríguez 1970: 12); y, El busto de doña Leonor: cuentos de juventud (1998), en el que en escenarios más urbanos que rurales, de la Sierra y la Costa ecuatoriana, Rojas trata las más disímiles preocupaciones humanas, comenzando por las que le inquietan en su condición de abogado, "agricultor de escritorio", escritor de narrativa de ficción, crítico literario y militante político o amigo distanciado, y por lo mismo cuestionador, de las prácticas del socialismo ecuatoriano (cf. Salazar 2010: 10-11).

Es necesario precisar que si bien la crítica e historiografía literaria ecuatoriana ha puesto como límite para la vigencia del realismo social la publicación de la novela El éxodo de Yangana (1949), de Ángel Felicísimo Rojas, es de justicia reconocer que algunos autores más jóvenes que editaron su primigenia obra cuentística en la década subsiguiente también se les debe considerar dentro del 
realismo social e indigenismo, "porque la narrativa de este período seguía siendo un apéndice de esa narrativa del realismo social de los años treinta" (Calderón 1997: 16).

Expresión de esta prolongación del realismo social constituyen cuentistas como Pedro Jorge Vera (1914-1999), con una docena de libros de cuentos publicados: La guamoteña (1946), Luto eterno (1953), Un ataúd abandonado (1968), Los mandamientos de la ley de Dios (1972), Cuentos escogidos (1976), Jesús ha vuelto (1978), Nada más que cuentos (1979), El destino (1984), jAh los militares! (1985), Cuentos duros (1990), La muerte siempre gana (1995); Doce cuentos de la historia (1997), en los cuales demuestra que siempre se mantuvo cercano a la estética realista del periodo anterior. En cuanto al estilo personal suyo, este se caracteriza porque sabe privilegiar "ciertos rasgos, gestos y detalles de la realidad representada en el afán por dar cuenta de un mundo de vida que solo puede ser abordado desde una mirada atenta a escenas que funcionan como clave de interpretación" (Ortega 2004: 44).

Desde esta misma perspectiva realista social, el multifacético escritor esmeraldeño Adalberto Ortiz (1914-2003) publica los libros de cuentos: Los contrabandistas (1945), La mala espalda (1952) y La entundada (1971), en ellos el autor afrodescendiente se orienta "hacia la búsqueda de formas narrativas y poéticas diversas que ponen en juego temas de negritud y de mestizos así como inquietud de matriz filosófica que indagan ciertas constantes humanas frente al problemático crecimiento de nuestras ciudades periféricas" (Ortega 2004: 31).

Otra clara evidencia de la prolongación del indigenismo y del realismo social de las dos décadas anteriores constituye Mary Corylé -seudónimo de María Ramona Cordero y León- (1901-1978), quien inició la publicación de su obra cuentística desde dos décadas antes, con La pancha (1933), Pobre Chapita (1933) y la continuó con Mundo pequeño (1948) y Gleba (1952). Al valorar la obra cuentística de esta autora, el crítico Miguel Donoso Pareja subraya que la narradora cuencana "sitúa sus mejores textos en el campo, aunque hace algunas incursiones urbanas. Su escritura, muy en los términos del realismo social, es básicamente de protesta y denuncia. Por momentos cae en lo declamatorio y discursivo, con lo que se acerca peligrosamente a las tesis del realismo socialista" (Donoso 1997: 35). En coherencia con las temáticas abordadas, los cuentos de Mary Corylé "evidencian un manejo magistral de las formas del habla popular, del diálogo coloquial que da cuenta del humor, la idiosincrasia, y los miedos y deseos más íntimos de sus personajes” (Ortega 2004: 36-37).

\section{Conclusiones}

La consolidación del cuento como género literario en el Ecuador se produce con el surgimiento y predominio del realismo social e indigenismo, en las décadas de los veinte, treinta y cuarenta del siglo XX, con la presencia de una pléyade de narradores dignos de memoria, tales como: José de la Cuadra, Leopoldo Benites Vinueza, Pablo Palacio, Jorge Icaza, Demetrio Aguilera Malta, Joaquín Gallegos Lara, Humberto Salvador, Ángel Felicísimo Rojas y Enrique Gil Gilbert. Es más, esta tendencia realista se prolonga, en las dos décadas subsiguientes con la obra cuentística de algunos autores nacidos en años posteriores, como Pedro Jorge Vera, Adalberto Ortiz y María Corylé.

De una valoración conjunta del cuento ecuatoriano publicado durante la época de predominio del realismo social e indigenista se advierte que, en consonancia con las ideologías políticas 
y estéticas que les dotaron de nuevo impulso se abordan las problemáticas que antes no habían sido consideradas; puesto que en la obra cuentística de los narradores adscritos a esta tendencia socio literaria se incorporan como protagonistas a personajes provenientes de los sectores sociales hasta entonces totalmente relegados de todo tipo de participación como los indios, los cholos y los montuvios.

En lo formal, como es fácil advertirlo de la lectura de las obras de narrativa adscritas a la tendencia realista, la mayoría de los cuentos publicados durante estos años no sobresalen por su perfección técnica ni por su refinamiento artístico, sino por ser una escritura de gran economía estilística, altamente expresiva e impugnadora de todas las formas anteriormente dominantes. En ella se incorpora el habla popular propia del indígena, el montuvio, el negro y el habitante marginal de las urbes y los sectores rurales; y, es parte, además, de un proyecto global de creación de una cultura nacional y popular, hasta ese momento aún inexistente en el Ecuador.

\section{Referencias bibliográficas}

Calderón Chico, C. (1997). 40 cuentos ecuatorianos: narrativa guayaquileña de fin de siglo. Guayaquil: Manglar Editores.

Córdova, C. J. (2008). El habla del Ecuador: diccionario de ecuatorianismos. Quito: Casa de la Cultura Ecuatoriana "Benjamín Carrión".

Cuadra, J. de la. (2003). ¿Feísmo? ¿Realismo? In Obras completas. (Tomo 2) (pp. 469-471). 2a ed. Quito: Casa de la Cultura Ecuatoriana "Benjamín Carrión".

Donoso Pareja, M. (1984). (estudio introductorio).In Los grandes de la década del 30. Quito: El Conejo.

- (1997). (estudio introductorio y notas). In Antología de narradoras ecuatorianas. Quito: Libresa.

Estébanez Calderón, D. (1999). Diccionario de términos literarios. Madrid: Alianza.

Martínez Gómez, J. (2015). Evolución del cuento ecuatoriano en el siglo XX. INTI. Revista de Literatura Hispánica, 80-81, 253-285.

Ortega Caicedo, A. (2004). (selección y presentación). In Antología esencial Ecuador siglo XX: el cuento. Quito: Eskeletra.

. (2011). El cuento en el período. In A. Ortega Caicedo (coord..), Historia de las literaturas del Ecuador. (vol. VII) Período1960-2000 (Primera parte) (pp. 175-218). Quito: Corporación Editora Nacional / Universidad Andina Simón Bolívar.

Proaño Arandi, F. (2007). La narrativa en el período. In J. Dávila Vázquez (Coord.), Historia de las literaturas del Ecuador (vol. 5) Período 1925-1960 (Primera parte) (pp. 121-167). Quito: Corporación Editora Nacional / Universidad Andina Simón Bolívar.

Real Academia Española. (2014). Diccionario de la lengua española. 23a ed. Madrid: Espasa Calpe.

Robles, H. (2000). A punta de risa (vanguardia / posmodernidad y la vigencia de su obra). In P. Palacio,

Obras completas. Edición crítica coordinada por W. Corral (vol. 41) (pp. 310-325). Madrid: ALLCA XX. (Colección Archivos).

Rodríguez Castello, H. (Comp.). (1970). Cuento de la generación del 30. Guayaquil/Quito: Ariel.

Rojas, Á. F. (1948). La Novela Ecuatoriana. México: Fondo de Cultura Económica. 
Salazar Estrada, Y. (2010). El pensamiento liberal y socialista en la obra de Ángel Felicísimo Rojas. Loja: Casa de la Cultura Ecuatoriana "Benjamín Carrión". . (2016). El cuento ecuatoriano. Inédito.

Sánchez Ramos, J. E. (2015). ¿Montubio o montuvio? El Telégrafo <www.eltelegrafo.com.ec/>.

Ubidia, A. (2006). Un siglo del relato ecuatoriano. In F. Corral Burbano De Lara, Testigo del siglo: el Ecuador visto a través de diario El Comercio, 1906-2006. Quito: El Comercio.

Valencia, L. (2000). El síndrome de Falcón. In P. Palacio, Obras completas. Edición crítica coordinada por W. Corral (vol. 41) (pp. 331-345). Madrid: ALLCA XX. (Colección Archivos). . (2008). Ecuador y el síndrome de Falcón. Babelia. <www.leonardovalencia.com/descarga/babelia_LeonardoValencia_22032008.pdf >.

Villanueva, D. (2004). Teorías del realismo literario. Madrid: Biblioteca Nueva.

Vintimilla, M. A. (1985). Los años treinta: el realismo y la nueva nación. In A. Carrasco Vintimilla, et al., Literatura y cultura nacional en el Ecuador: los proyectos ideológicos y la realidad social 1895-1944 (pp.

249-285). Cuenca: Casa de la Cultura Ecuatoriana "Benjamín Carrión”. 